\title{
Postsynaptic Complex Spike Bursting Enables the Induction of LTP by Theta Frequency Synaptic Stimulation
}

\author{
Mark J. Thomas, ${ }^{1}$ Ayako M. Watabe, ${ }^{2}$ Teena D. Moody, ${ }^{1}$ Michael Makhinson, ${ }^{1}$ and Thomas J. O'Dell ${ }^{2}$ \\ 1/nterdepartmental PhD Program for Neuroscience and ${ }^{2}$ Department of Physiology, School of Medicine, University of \\ California, Los Angeles, Los Angeles, California 90095
}

\begin{abstract}
Long-term potentiation (LTP), a persistent enhancement of synaptic transmission that may be involved in some forms of learning and memory, is induced at excitatory synapses in the CA1 region of the hippocampus by coincident presynaptic and postsynaptic activity. Although action potentials backpropagating into dendrites of hippocampal pyramidal cells provide sufficient postsynaptic activity to induce LTP under some in vitro conditions, it is not known whether LTP can be induced by patterns of postsynaptic action potential firing that occur in these cells in vivo. Here we report that a characteristic in vivo pattern of action potential generation in CA1 pyramidal cells
\end{abstract}

known as the complex spike burst enables the induction of LTP during theta frequency synaptic stimulation in the CA1 region of hippocampal slices maintained in vitro. Our results suggest that complex spike bursting may have an important role in synaptic processes involved in learning and memory formation, perhaps by producing a highly sensitive postsynaptic state during which even low frequencies of presynaptic activity can induce LTP.

Key words: long-term potentiation; complex spike burst; hippocampus; pyramidal cells; synaptic transmission; learning and memory
At many excitatory synapses, coincident activity in the presynaptic terminal and postsynaptic cell induces long-term potentiation (LTP), a persistent enhancement of synaptic transmission thought to have a role in certain forms of learning and memory (Bliss and Collingridge, 1993). The significance of coincident presynaptic and postsynaptic activity in the induction of LTP lies in the fact that it provides the simultaneous release of glutamate and postsynaptic membrane depolarization necessary for activation of NMDA-type glutamate receptors. Calcium influx through NMDA receptor ion channels in turn triggers a complex, protein kinase-dependent signaling pathway ultimately responsible for the modifications that enhance synaptic transmission (Bliss and Collingridge, 1993).

Until recently, the strong postsynaptic depolarization required for NMDA receptor activation and LTP induction was thought to arise primarily from the temporal and spatial summation of EPSPs during high-frequency stimulation of multiple presynaptic fibers (Nicoll et al., 1988; Gustafsson and Wigström, 1990; Debanne et al., 1996). However, recent findings showing that action potentials initiated near the cell body back-propagate into pyramidal cell dendrites (Magee and Johnston, 1995; Spruston et al., 1995) suggest that dendritic action potentials may provide an additional means of achieving the postsynaptic depolarization needed to activate NMDA receptors and induce LTP. Indeed, EPSPs paired with back-propagating dendritic action potentials can induce LTP under some in vitro conditions (Scharfman and

\footnotetext{
Received April 3, 1998; revised June 18, 1998; accepted June 26, 1998.

This work was supported by grants from the National Institute of Mental Health, the Klingenstein Fund, and the Pew Charitable Trusts to T.J.O. T.J.O. is a member of the University of California Los Angeles Brain Research Institute. We are grateful to D. V. Buonomano, D. Glanzman, and F. Krasne for comments on an earlier version of this manuscript.

M.J.T. and A.M.W. made equal contributions to this work.

Correspondence should be addressed to Dr. Thomas O'Dell, Department of Physiology, University of California Los Angeles School of Medicine, 53-231 Center for the Health Sciences, 10833 Le Conte Avenue, Los Angeles, CA 90095.

Copyright (C) 1998 Society for Neuroscience $0270-6474 / 98 / 187118-09 \$ 05.00 / 0$
}

Sarvey, 1985; Magee and Johnston, 1997; Markram et al., 1997). Although these findings suggest that dendritic action potentials may have an important role in the induction of LTP, it is not yet known whether patterns of action potential firing observed in CA1 pyramidal cells in vivo are sufficient and/or necessary for LTP induction.

In vivo, hippocampal CA1 pyramidal cells generate action potentials either as single, isolated spikes or in high-frequency bursts of two or more action potentials that progressively decline in amplitude and increase in duration during the burst (Kandel and Spencer, 1961; Ranck, 1973; Fox and Ranck, 1975; Suzuki and Smith, 1985). This second mode of firing, known as the complex spike burst, is a defining electrophysiological signature of hippocampal pyramidal cells (Ranck, 1973; Fox and Ranck, 1975) and may represent an important form of information coding in the hippocampus (Lisman, 1997). Complex spike bursts may also have an important role in hippocampal synaptic plasticity because patterns of presynaptic fiber stimulation that mimic complex spike bursting can, under certain conditions, induce LTP (Larson et al., 1986; Huerta and Lisman, 1993, 1995; Hölscher et al., 1997). Because action potentials during complex spike bursts backpropagate into CA1 pyramidal cell dendrites in vivo (Buzáki et al., 1996), complex spike bursts might also have an important postsynaptic role in the induction of LTP by providing the postsynaptic activity needed for NMDA receptor activation. Thus, to determine whether EPSPs paired with patterns of postsynaptic spiking that occur in CA1 pyramidal cells in vivo can induce LTP, we investigated the postsynaptic role of both single action potentials and complex spike bursts in the induction of LTP during theta frequency synaptic stimulation.

\section{MATERIALS AND METHODS}

Transverse hippocampal slices, $400 \mu \mathrm{m}$ thick, were obtained from halothane-anesthetized male mice (C57BL/6) using standard techniques. Unless noted otherwise, all experiments were done using animals between 4 and 7 weeks of age. None of our findings varied with animal age. 
Although $5 \mathrm{~Hz}$ synaptic stimulation can induce long-term depression in slices from very young animals (Bolshakov and Siegelbaum, 1994; Oliet et al., 1997), it does not induce LTD in the CA1 region of hippocampal slices obtained from mice in the age range used in our experiments (Mayford et al., 1995; Thomas et al., 1996). Slices were maintained in an interface recording chamber (Fine Science Tools, Inc.) and perfused with an artificial mouse CSF (ACSF) consisting of (in mM): $124 \mathrm{NaCl}$, $4.4 \mathrm{KCl}, 25 \mathrm{NaHCO}_{3}, 1 \mathrm{NaH}_{2} \mathrm{PO}_{4}, 1.2 \mathrm{MgSO}_{4}, 2 \mathrm{CaCl}_{2}$, and 10 glucose (gassed with $95 \% \mathrm{O}_{2}$ and $5 \% \mathrm{CO}_{2}$; temperature, $30^{\circ} \mathrm{C}$ ). Schaffer collateral and commissural fibers were stimulated at $0.02 \mathrm{~Hz}$ with a bipolar nichrome wire stimulating electrode (0.02 msec duration pulses), and EPSPs evoked in CA1 pyramidal cells were recorded extracellularly in stratum radiatum with an ACSF-filled glass microelectrode (5-10 M $\Omega$ ). Glass microelectrodes $(60-120 \mathrm{M} \Omega)$ filled with $3 \mathrm{M} \mathrm{K}$-acetate or $2 \mathrm{M}$ $\mathrm{K}$-methylsulfate were used in intracellular recordings. Only cells with resting membrane potentials more negative than $-55 \mathrm{mV}$ and with overshooting action potential amplitudes were used. Stimulation intensity was adjusted to evoke field EPSPs (fEPSPs) that were $50 \%$ of the maximal fEPSP amplitude (strong intensity stimulation) or $20-25 \%$ of the maximal response (weak intensity stimulation). In two pathway experiments, independence of the fibers activated by two stimulating electrodes was confirmed by the lack of paired-pulse facilitation when one pathway was stimulated $50 \mathrm{msec}$ after the other. CA1 pyramidal cells were antidromically activated using a stimulating electrode placed in the alveus and stimulation intensities sufficient to evoke near-maximal antidromic population spikes (recorded with an extracellular electrode in stratum radiatum). Slices showing any evidence of contamination of the antidromic response by activation of fibers in stratum oriens were not used.

All stimulation protocols as well as data acquisition and analysis were performed using Experimenter's Workbench (Data Wave Technologies Inc.). Negative-going spikes appearing in fEPSP recordings were manually counted off-line by visually inspecting each trace recorded during 5 $\mathrm{Hz}$ stimulation. This analysis was done in a blind manner. All values are reported as mean \pm SEM, and Student's $t$ tests were used to assess statistical significance.

Salts used in the ACSF were purchased from Sigma (St. Louis, MO). All other compounds were purchased from Research Biochemicals (Natick, MA). Concentrated stock solutions of nifedipine and nimodipine (in dimethylsulfoxide) were prepared fresh daily under dim light, and experiments were done in the dark to minimize light exposure.

\section{RESULTS}

\section{Five hertz synaptic stimulation induces postsynaptic complex spike bursting}

Although complex spike bursting is a characteristic mode of action potential firing in vivo (Kandel and Spencer, 1961; Ranck, 1973; Fox and Ranck, 1975), relatively few CA1 pyramidal cells in the in vitro hippocampal slice preparation generate complex spike-like bursts of action potentials when depolarized by current injected through an intracellular microelectrode (Jensen et al., 1996). The paucity of cells that generate complex spike bursts under physiological conditions in vitro thus hinders an analysis of how this mode of action potential firing may be involved in the induction of LTP. However, as has been observed in vivo (Suzuki and Smith, 1988), we observed that CA1 pyramidal cells in the in vitro hippocampal slice preparation fire complex spike-like bursts of action potentials during trains of synaptic stimulation delivered at $5 \mathrm{~Hz}$, a stimulation frequency that corresponds to the hippocampal theta rhythm that occurs in vivo (Bland, 1990). As shown in Figure $1 A$, during 5 $\mathrm{Hz}$ stimulation negative-going spikes superimposed on the fEPSPs appeared after $\sim 40-50$ stimulation pulses and gradually grew in number and amplitude. Intracellular recordings from individual CA1 pyramidal cells $(n=9)$ confirmed that the spikes seen in the extracellular recordings were attributable to bursts of action potentials in the postsynaptic CA1 pyramidal cells (Fig. 1B). Moreover, we found that bursting during $5 \mathrm{~Hz}$ stimulation was prevented in CA1 pyramidal cells impaled with microelectrodes containing the $\mathrm{Na}^{+}$channel blocker QX-314 (100 mm; $n=7$; Fig. $\left.1 B\right)$, indicating that the bursts are generated postsynaptically in a voltage-sensitive $\mathrm{Na}^{+}$channel-dependent manner. The interspike intervals (5-7 msec), progressive decrease in spike amplitude, and progressive increase in spike duration during these $5 \mathrm{~Hz}$ stimulation-induced bursts are characteristic electrophysiological features of complex spike bursts recorded in vivo (Kandel and Spencer, 1961; Ranck, 1973; Fox and Ranck, 1975).

In agreement with previous reports indicating that a highly TTX-sensitive, persistent $\mathrm{Na}^{+}$conductance has a crucial role in burst generation in CA1 pyramidal cells (Azouz et al., 1996; Jensen et al., 1996), we found that a brief (10 min) application of TTX (250 nM) had little effect on excitatory synaptic transmission (see below) or on the generation of single action potentials but produced a near-complete suppression of complex spike bursting (Fig. 1C). During intracellular recordings from CA1 pyramidal cells we observed that when 150 pulses of $5 \mathrm{~Hz}$ stimulation were delivered in the absence of TTX, EPSPs elicited complex spike bursting (defined as two or more action potentials with interspike intervals of $<10 \mathrm{msec}$ ) on $61 \pm 6 \%$ of stimulation pulses ( $n=9$ cells). In contrast, although EPSPs reliably evoked single action potentials during 150 pulses of $5 \mathrm{~Hz}$ stimulation in the presence of $250 \mathrm{nM}$ TTX (10 min application), complex spike bursts were observed on only $3 \pm 2 \%$ of the stimulation pulses ( $n=9$ cells $)$.

\section{Five hertz synaptic stimulation induces an associative, NMDA receptor-dependent form of LTP}

If complex spike bursts provide a sufficient level of dendritic depolarization to relieve the voltage-dependent $\mathrm{Mg}^{2+}$ ion block of the NMDA receptor, then the EPSP-evoked bursts that occur during $5 \mathrm{~Hz}$ stimulation should induce LTP. As shown in Figure $2 A, 30 \mathrm{sec}$ of $5 \mathrm{~Hz}$ stimulation induced a persistent potentiation of synaptic transmission that was significantly reduced when $5 \mathrm{~Hz}$ stimulation was delivered in the presence of the NMDA receptor blocker 2-amino-5-phosphonovaleric acid (100 $\mu \mathrm{M}$ DL-APV). As is the case for certain high-frequency stimulation protocols (Grover and Teyler, 1990; Johnston et al., 1992; Ito et al., 1995), $5 \mathrm{~Hz}$ stimulation appears to induce LTP through both NMDA receptor-dependent and -independent signaling pathways because a small, but significant $(p<0.01)$, potentiation was still evident $45 \mathrm{~min}$ after $5 \mathrm{~Hz}$ stimulation in APV. In experiments in which we doubled the effective concentration of APV by using $100 \mu \mathrm{M}$ D-APV a similar APV-resistant potentiation was also induced (fEPSPs were potentiated to $117.8 \pm 2.5 \%$ of baseline 45 min after $5 \mathrm{~Hz}$ stimulation; $n=4$ ), suggesting that the residual potentiation induced in the presence of APV is not attributable to incomplete NMDA receptor blockade. NMDA receptorindependent LTP of excitatory synaptic transmission in the CA1 region of the hippocampus is thought to be caused by $\mathrm{Ca}^{2+}$ influx through voltage-sensitive $\mathrm{Ca}^{2+}$ channels, because inhibitors of L-type (Grover and Teyler, 1990) or T-type (Ito et al., 1995, Magee and Johnston, 1997) $\mathrm{Ca}^{2+}$ channels can block this component of high-frequency stimulation-induced LTP. We found that $5 \mathrm{~Hz}$ stimulation-induced LTP was not inhibited by the L-type $\mathrm{Ca}^{2+}$ channel antagonists nifedipine and nimodipine [fEPSPs were potentiated to $151.4 \pm 11.3 \%$ of baseline $(n=5) 45$ min after $5 \mathrm{~Hz}$ stimulation in $10 \mu \mathrm{M}$ nifedipine and to $153.2 \pm$ $10.2 \%$ of baseline $(n=5)$ after $5 \mathrm{~Hz}$ stimulation in $20 \mu \mathrm{M}$ nimodipine]. However, the T-type $\mathrm{Ca}^{2+}$ channel blocker $\mathrm{Ni}^{2+}$ significantly reduced the amount of potentiation induced by $5 \mathrm{~Hz}$ stimulation [fEPSPs were $123.6 \pm 4.4 \%$ of baseline 45 min after $5 \mathrm{~Hz}$ stimulation in $50 \mu \mathrm{M} \mathrm{NiCl}{ }_{2}(n=8)$ compared with $153.7 \pm$ $7.7 \%$ of baseline in paired control experiments $(n=8) ; t_{(14)}=$ 3.38; $p<0.005]$. In the presence of both $50 \mu \mathrm{M} \mathrm{NiCl} l_{2}$ and $100 \mu \mathrm{M}$ 

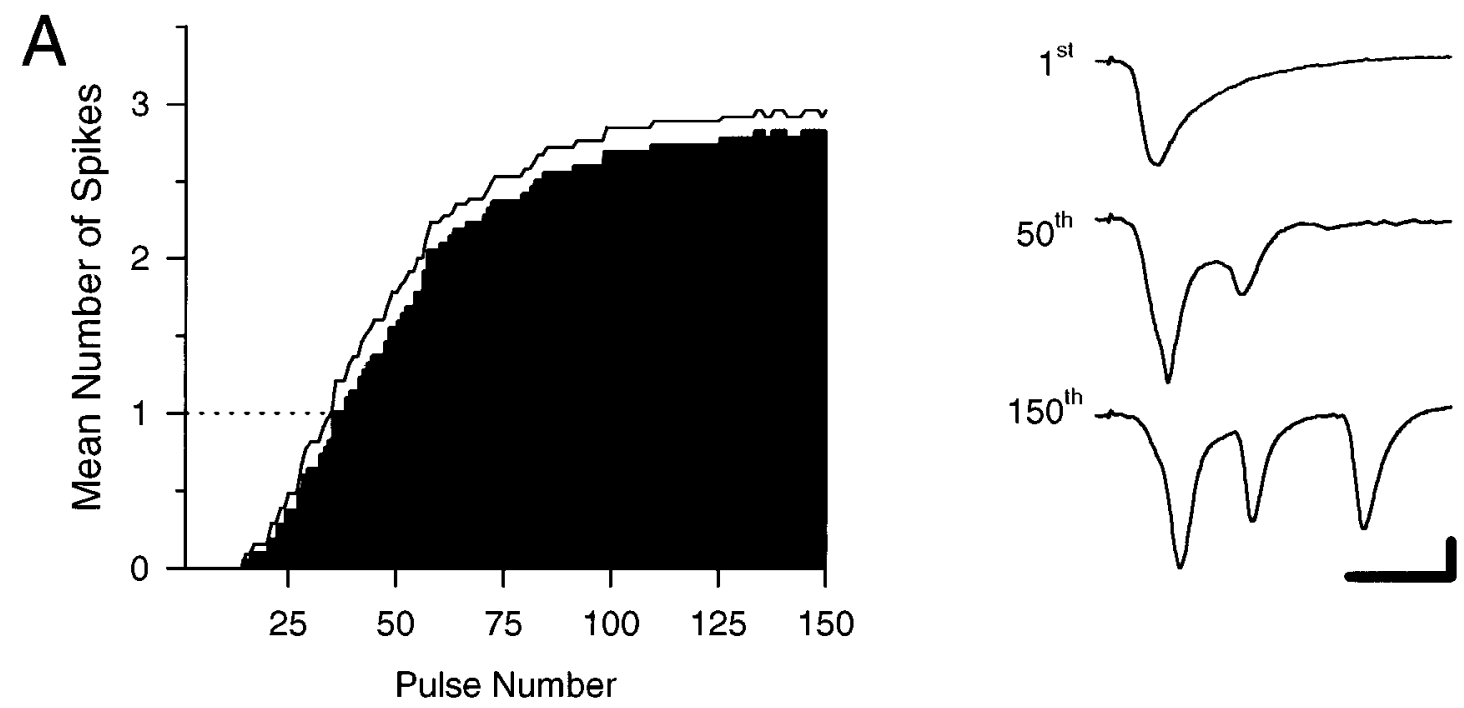
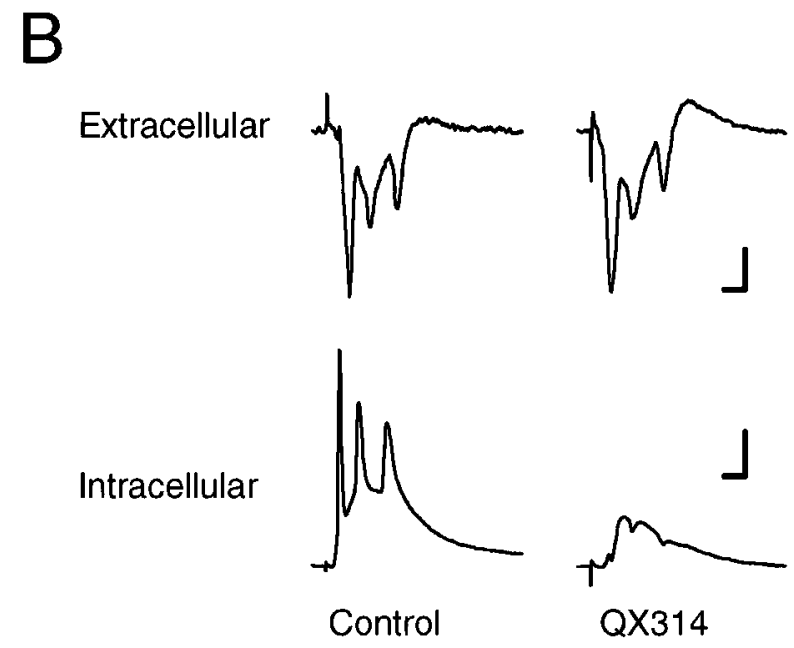

C

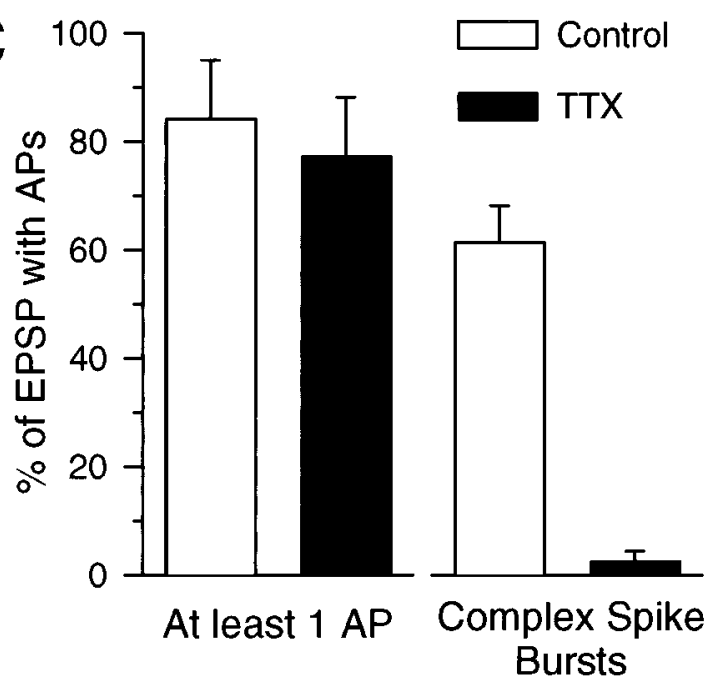

Figure 1. Complex spike bursting in CA1 pyramidal cells is induced by $5 \mathrm{~Hz}$ stimulation. $A$, The histogram shows the mean number of spikes evoked by each stimulation pulse during $30 \mathrm{sec}$ of $5 \mathrm{~Hz}$ stimulation $(n=22)$. On average, complex spike-like bursting (number of spikes $>1)$ does not begin until the 40th pulse of $5 \mathrm{~Hz}$ stimulation. The line indicates the mean $+1 \mathrm{SEM}$. The traces, right, show fEPSPs recorded in stratum radiatum at the indicated time points during a 30-sec-long train of $5 \mathrm{~Hz}$ stimulation. Note the negative (downward) spikes that appear in the last two evoked responses. Calibration: $2 \mathrm{mV}, 10 \mathrm{msec}$. B. Examples of simultaneously recorded field (top) and intracellular (bottom) responses during $5 \mathrm{~Hz}$ stimulation. Note that in control recordings (left) the negative-going spikes present in the extracellular recording correspond to action potentials in the intracellular recording. Although strong bursting is evident in the extracellular recording, no bursting occurs in the cell impaled with a QX-314-containing microelectrode (right). Calibration: $2 \mathrm{mV}, 5 \mathrm{msec}$ (extracellular traces); $15 \mathrm{mV}, 5 \mathrm{msec}$ (intracellular traces). $C$, The histograms show the percentage of EPSPs (mean \pm SEM) that evoke at least one action potential (left) or a complex spike burst (right) during 150 pulses of $5 \mathrm{~Hz}$ stimulation in the absence (open bars; $n=9$ cells) or presence of $250 \mathrm{nM}$ TTX ( filled bars; $n=9$ cells). In the absence of TTX, the time course of EPSP-evoked complex spike bursting recorded intracellularly was similar to that determined from extracellular recordings as shown in $A$.

DL-APV, fEPSPs were $107.5 \pm 2.7 \%$ of baseline 45 min after $5 \mathrm{~Hz}$ stimulation $(n=8)$ compared with $151.1 \pm 5.8 \%$ of baseline in paired control experiments $(n=6)$. Thus, activation of both NMDA receptors and T-type $\mathrm{Ca}^{2+}$ channels appears to contribute to the induction of LTP by $5 \mathrm{~Hz}$ stimulation. Nifedipine, nimodipine, $\mathrm{Ni}^{2+}$, and APV did not block $5 \mathrm{~Hz}$ stimulationinduced complex spike bursting, suggesting that activation of L-type and T-type $\mathrm{Ca}^{2+}$ channels as well as NMDA receptors is not required for complex spike bursting.

We further characterized the potentiation induced by $5 \mathrm{~Hz}$ stimulation by investigating the effects of presynaptic fiber stimulation strength on the induction of LTP. Although strongintensity $5 \mathrm{~Hz}$ stimulation induced LTP, weak-intensity stimulation failed to induce both complex spike bursting and LTP (Fig.
$2 B)$. LTP could be induced in a group of synapses activated by weak-intensity presynaptic stimulation, however, if these synapses were coactivated during $5 \mathrm{~Hz}$ stimulation with a strongly stimulated independent group of synaptic inputs that elicited complex spike bursting (Fig. 2B). Thus, like high-frequency stimulationinduced LTP (Nicoll et al., 1988, Gustafsson and Wigström, 1990; Bliss and Collingridge, 1993), $5 \mathrm{~Hz}$ stimulation induces an associative form of LTP whereby independent groups of synapses can interact in a positive manner to induce LTP.

\section{Complex spike bursting is required for the induction of LTP by $5 \mathrm{~Hz}$ stimulation}

To determine whether complex spike bursts are required for the induction of LTP during $5 \mathrm{~Hz}$ stimulation, we examined whether 

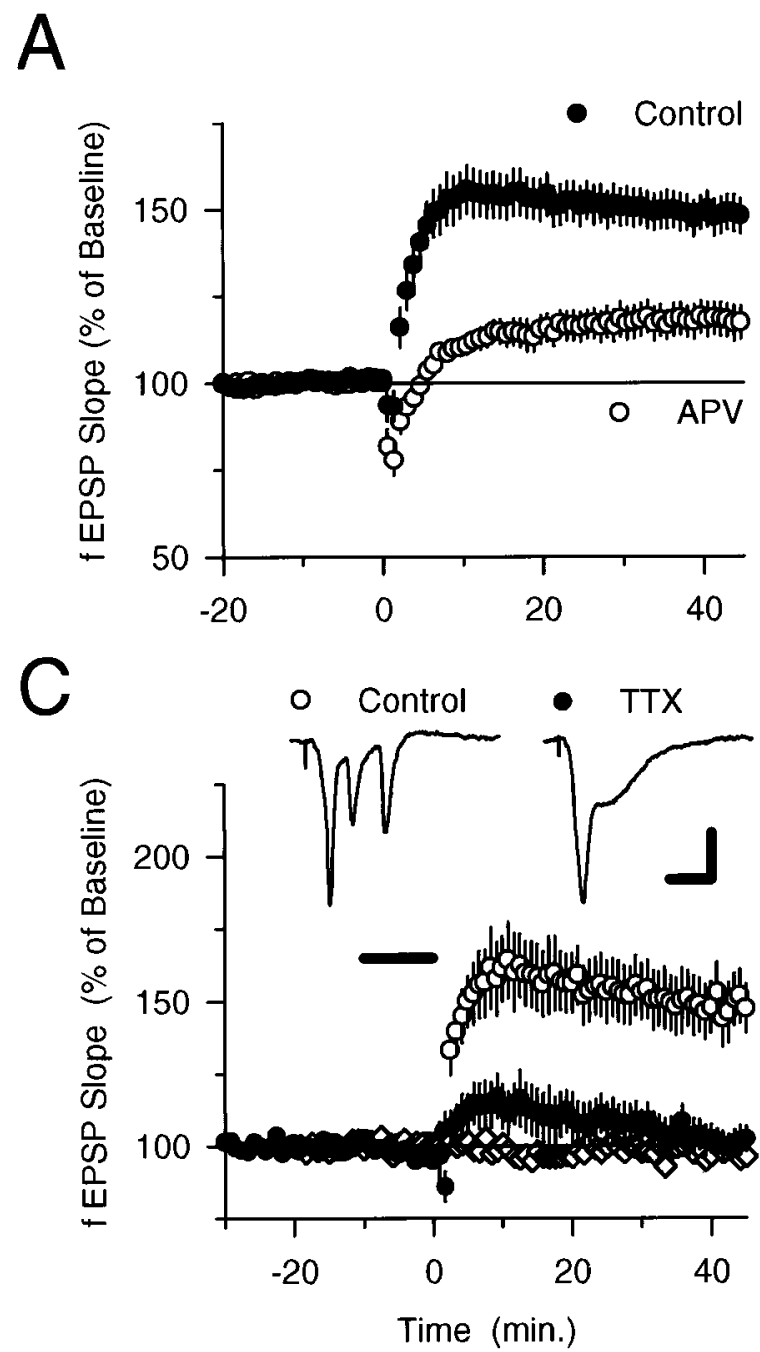

B

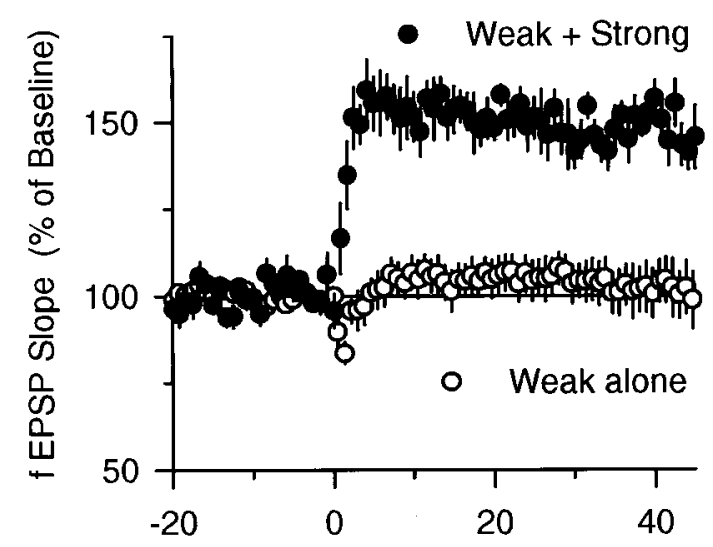

D

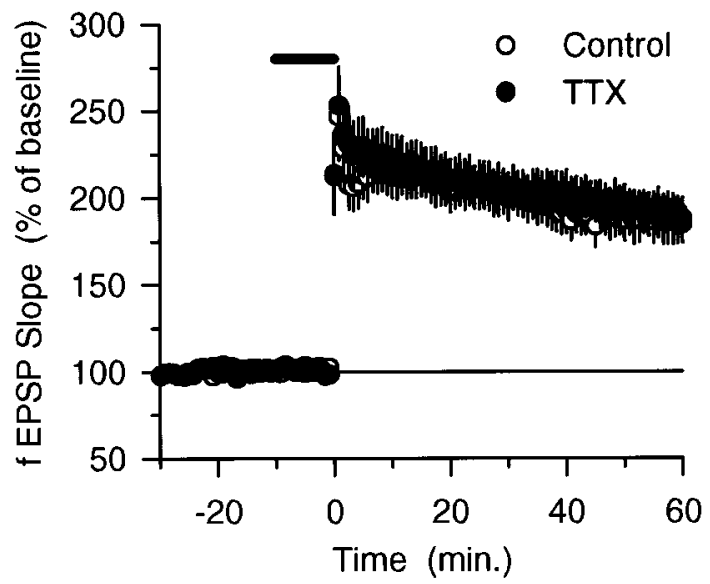

Figure 2. Complex spike bursts enable LTP induction during $5 \mathrm{~Hz}$ stimulation. $A$, A $30 \mathrm{sec}$ train of $5 \mathrm{~Hz}$ stimulation was delivered (at time $=0$ ). In control experiments ( filled symbols) fEPSPs were potentiated to $148.6 \pm 5.3 \%$ of baseline $(n=27) 45$ min after 5 Hz stimulation, whereas fEPSPs were $117.3 \pm 4.8 \%$ of baseline after $5 \mathrm{~Hz}$ stimulation in $100 \mu \mathrm{M}$ DL-APV (open symbols; $n=7$; significantly less than control, $p<0.01$ ). $B$, Weak-intensity stimulation of a single pathway (open symbols; $n=9$ ) failed to induce a persistent change in synaptic transmission. In contrast, LTP was induced when a pathway activated with weak-intensity stimulation ( filled symbols; $n=5$ ) was coactivated during $5 \mathrm{~Hz}$ stimulation with an independent pathway stimulated at a high intensity. For clarity the results from activation of the strong pathway are not shown (EPSPs in the pathway activated by strong-intensity $5 \mathrm{~Hz}$ stimulation were potentiated to $166.7 \pm 11.0 \%$ of baseline; $n=5$ ). $C$, A 10 min bath application of $250 \mathrm{~nm}$ TTX (indicated by the bar) blocks the induction of LTP by $5 \mathrm{~Hz}$ stimulation. Forty-five minutes after $5 \mathrm{~Hz}$ stimulation in TTX ( filled circles), fEPSPs were $102.4 \pm 4.2 \%$ of baseline $(n=7)$, whereas synaptic transmission was potentiated to $147.3 \pm 8.5 \%$ of baseline in control experiments (no TTX; open circles; $n=10)$. Bath application of TTX alone had no effect on synaptic transmission (diamonds; $n=5$ ). Traces are fEPSPs recorded at the end of $5 \mathrm{~Hz}$ stimulation in control and TTX experiments. Calibration: $2 \mathrm{mV}, 10 \mathrm{msec}$. $D$, TTX does not inhibit the induction of LTP by two trains of $100 \mathrm{~Hz}$ stimulation (1 sec duration; intertrain interval $=10 \mathrm{sec}$, delivered at time $=0$ ). fEPSPs were potentiated to $187.0 \pm 12.8 \%$ of baseline 60 min after tetanus in control experiments (open symbols; $n=7$ ) and were potentiated to $188.3 \pm 9.1 \%$ of baseline after $100 \mathrm{~Hz}$ stimulation in $250 \mathrm{~nm}$ TTX (indicated by the bar, filled symbols; $n=7)$.

pharmacologically suppressing complex spike bursting could prevent the induction of LTP by strong-intensity $5 \mathrm{~Hz}$ stimulation. Because T-type calcium channels appear to be involved in the induction of LTP by $5 \mathrm{~Hz}$ stimulation, we did not attempt to use intracellular electrodes containing the $\mathrm{Na}^{+}$channel blocker QX314 in these experiments because this compound also inhibits T-type $\mathrm{Ca}^{2+}$ channels (Talbot and Sayer, 1996). Instead, because our earlier experiments confirmed previous findings that low concentrations of TTX inhibit bursting with little effect on the generation of single action potentials (Azouz et al., 1996), we examined whether LTP induction was blocked when complex spike bursting during $5 \mathrm{~Hz}$ stimulation was suppressed by TTX. Although a short application of $250 \mathrm{~nm}$ TTX had no effect on baseline synaptic transmission, it strongly suppressed complex spike bursting during $5 \mathrm{~Hz}$ stimulation and blocked the induction of LTP (Fig. 2C). In contrast, $250 \mathrm{~nm}$ TTX had no effect on high-frequency stimulation-induced LTP (Fig. 2D). Thus, TTX does not have generalized effects on synaptic transmission that prevent the induction of LTP, suggesting that the TTX block of 5 $\mathrm{Hz}$ stimulation-induced LTP is caused by the suppression of complex spike bursting. Moreover, because these concentrations of TTX have little effect on the ability of EPSPs to evoke single postsynaptic action potentials (Fig. $1 C$ ), the TTX block of $5 \mathrm{~Hz}$ stimulation-induced LTP suggests that bursts, rather than single action potentials, are specifically required for LTP induction.

We also examined the need for complex spike bursting in $5 \mathrm{~Hz}$ 

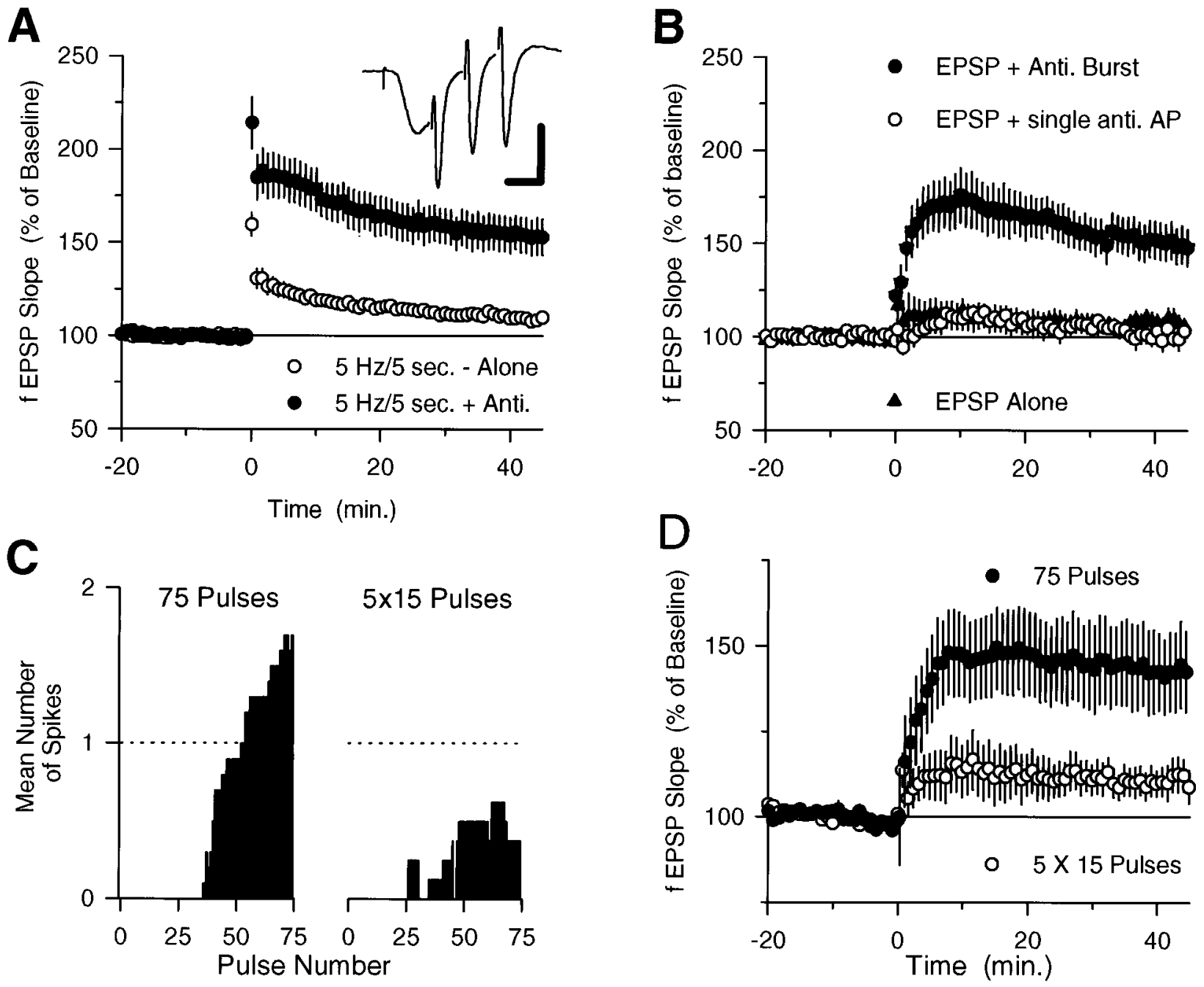

Figure 3. A, Twenty-five pulses of $5 \mathrm{~Hz}$ synaptic stimulation alone has little persistent effect on synaptic transmission (open symbols; fEPSPs were $109.7 \pm 2.8 \%$ of baseline 45 min after $5 \mathrm{~Hz}$ stimulation; $n=22$ ) but induces LTP when paired with complex spike burst-like antidromic stimulation ( filled symbols; fEPSPs were potentiated to $152.9 \pm 9.63 \%$ of baseline; $n=14$; significantly greater than synaptic stimulation alone, $p<0.005)$. Inset, Response during pairing of synaptic and antidromic burst stimulation (calibration: $5 \mathrm{mV}, 5 \mathrm{msec}$ ). These experiments were done using slices from animals between 3 and 4 weeks of age ( $n=14$ for $5 \mathrm{~Hz}$ stimulation alone; $n=8$ for $5 \mathrm{~Hz}$ stimulation paired with antidromic stimulation) and between 5 and 7 weeks of age ( $n=8$ for $5 \mathrm{~Hz}$ stimulation alone; $n=6$ for $5 \mathrm{~Hz}$ stimulation paired with antidromic stimulation). The results from these two groups of animals were not different and have been combined. $B$, Complex spike burst-like antidromic stimulation induces LTP when paired with 50 pulses of $2.5 \mathrm{~Hz}$ synaptic stimulation ( filled circles; $n=9$ ), whereas pairing EPSPs with a single antidromic stimulation pulse has no lasting effect on synaptic strength (open circles; $n=6$; EPSPs were $103.2 \pm 4.4 \%$ of baseline). Fifty pulses of $2.5 \mathrm{~Hz}$ stimulation alone had no effect on synaptic strength ( filled triangles; $n=8)$. $C$, Mean number of spikes in fEPSP recordings evoked by each of 75 pulses of $5 \mathrm{~Hz}$ stimulation during the continuous train (right; SEM values ranged from 0 to 0.46 ) and during five trains of 15 pulses (left; intertrain interval, 7 sec; SEM values ranged from 0 to 0.41 ). $D$, Seventy-five pulses of $5 \mathrm{~Hz}$ stimulation induced LTP when delivered as a continuous train (open symbols; fEPSPs were potentiated to $142.7 \pm 11.9 \%$ of baseline; $n=8$ ) but had little effect on synaptic transmission when delivered as five trains of 15 pulses ( filled symbols; EPSPs were $110.72 \pm 5.2 \%$ of baseline; $n=8$; significantly less than potentiation induced by continuous 75 pulse train, $p<0.025$ ). Data from the same experiments shown in $C$.

stimulation-induced LTP by determining whether LTP could be induced by pairing EPSPs with antidromically stimulated bursts of action potentials that mimicked complex spike bursting (three actions potentials at $200 \mathrm{~Hz}$, beginning $7 \mathrm{msec}$ after the start of the EPSP; Fig. $3 A$, inset). Although strong-intensity $5 \mathrm{~Hz}$ trains that terminated before complex spike bursting began $(5 \mathrm{~Hz}$ for 5 sec) induced little persistent change in synaptic strength, significant LTP was induced when this short train of $5 \mathrm{~Hz}$ stimulation was paired with antidromic stimulation that mimicked complex spike bursting (Fig. 3A). Antidromic stimulation alone had no effect on synaptic transmission ( $n=3$; data not shown). It has been reported (Jester et al., 1995) that pairing antidromic action potentials with orthodromic synaptic stimulation fails to induce
LTP in the CA1 region of the hippocampus. There are numerous methodological differences between our experiments and those described in this report, especially with respect to the patterns and numbers of antidromic and orthodromic stimulation pulses used during pairing. Although we have not investigated which of these variables account for these different results, we believe it is significant that in our experiments LTP was induced by stimulation protocols specifically designed to mimic EPSP-evoked complex spike bursting. We also observed that LTP could be induced by pairing complex spike-like antidromic stimulation with another low-frequency synaptic stimulation protocol $(50$ pulses at $2.5 \mathrm{~Hz})$ that alone failed to induce complex spike bursting and had no lasting effect on synaptic transmission (Fig. 3B). In these experi- 
ments fEPSPs were $105.6 \%$ of baseline 45 min after $2.5 \mathrm{~Hz}$ synaptic stimulation alone $(n=8)$ and $149.5 \pm 10.2 \%$ of baseline after pairing $2.5 \mathrm{~Hz}$ synaptic stimulation with antidromic bursts $(n=9)$. Consistent with the results from our experiments with TTX that suggest that EPSPs paired with single postsynaptic action potentials are not sufficient for LTP induction, a single pulse of antidromic stimulation paired with $2.5 \mathrm{~Hz}$ synaptic stimulation (delivered $7 \mathrm{msec}$ after the EPSP) failed to induce LTP (Fig. 3B).

Finally, because EPSPs evoked complex spike bursts with a characteristic delay after the start of a $5 \mathrm{~Hz}$ stimulation train, we also investigated whether delivering $5 \mathrm{~Hz}$ stimulation as a continuous train that elicited complex spike bursting or as several short groups of stimulation pulses that were not long enough for complex spike bursting to begin could affect the induction of LTP. We found that although 75 pulses of $5 \mathrm{~Hz}$ stimulation delivered as a continuous train induced complex spike bursting and LTP, 75 stimulation pulses delivered as five trains of 15 pulses (intertrain interval, $7 \mathrm{sec}$ ) failed to induce complex spike bursting and had little lasting effect on synaptic transmission (Fig. 3C,D).

\section{High levels of complex spike bursting are required for LTP induction during long trains of $5 \mathrm{~Hz}$ stimulation}

If the induction of LTP by low-frequency synaptic stimulation depends solely on EPSP and complex burst coincidence, then LTP should be reliably induced by all trains of stimulation that produce at least the minimal or threshold number of coincident EPSP and complex spike bursts needed to activate the NMDA receptor-dependent signaling pathways responsible for LTP. However, when we examined the effect of train duration on both complex spike bursting and LTP induction, the results clearly indicated that LTP was not simply induced after the occurrence of some threshold number of EPSP-evoked complex spike bursts. As shown in Figure $4 A$, during a 3 min long train of $5 \mathrm{~Hz}$ stimulation (900 pulses), complex spike bursting was prominent during the first 150 stimulation pulses and then gradually declined, terminating on average by the 300th stimulation pulse. When we examined the effects of different duration $5 \mathrm{~Hz}$ trains on the induction of LTP, we observed that when LTP was induced by 75 and 150 pulse trains of $5 \mathrm{~Hz}$ stimulation, shorter ( 25 pulses) or longer (300 and 900 pulses) trains had little persistent effect on synaptic strength (Fig. 4B). These results indicate that short trains of $5 \mathrm{~Hz}$ stimulation (25 pulses) that terminate before complex spike bursting begins fail to induce LTP and that by 75 pulses of $5 \mathrm{~Hz}$ stimulation a sufficient number of EPSP-evoked complex spike bursts $(27 \pm 5$, mean \pm SEM $)$ have occurred to induce LTP. Yet, when $5 \mathrm{~Hz}$ stimulation was continued for longer periods (300 and 900 pulses) no LTP was induced, even though the total number of EPSP-evoked complex spike bursts was six to nine times greater during longer trains of $5 \mathrm{~Hz}$ stimulation than during the 75 pulse train (Fig. $4 B$, inset). Thus, although EPSPevoked complex spike bursting can activate the NMDA receptordependent processes required for LTP induction, it appears that other cellular processes that inhibit LTP induction are also activated during longer trains of $5 \mathrm{~Hz}$ stimulation. Indeed, previous studies have shown that NMDA receptor activation can activate processes that increase the threshold for LTP induction and/or reverse previously established LTP (Fujii et al., 1991; Huang et al., 1992; O’Dell and Kandel, 1994). Based on previous observations that protein phosphatase inhibitors enhance the induction of LTP by long, but not short, trains of $5 \mathrm{~Hz}$ stimulation (Thomas et al., 1996) and prevent the reversal of previously established LTP by $5 \mathrm{~Hz}$ stimulation (O'Dell and Kandel, 1994), it seems likely that protein phosphatase activation importantly contributes to the inhibition of LTP induction during long trains of $5 \mathrm{~Hz}$ stimulation.

Modest levels of NMDA receptor activation during lowfrequency synaptic stimulation are thought to activate protein phosphatases by producing modest increases in intracellular calcium (Mulkey and Malenka, 1992; Lisman, 1994; Cummings et al., 1996). In contrast, more intense NMDA receptor activation is thought to elicit a larger increase in intracellular calcium that both activates the protein kinases directly responsible for inducing LTP (Bliss and Collingridge, 1993) and inhibits the activity of protein phosphatases that might oppose the induction of LTP (Lisman, 1994; Blitzer et al., 1995; Thomas et al., 1996). Because strong NMDA receptor activation can activate a signaling pathway that inhibits protein phosphatases, we investigated whether increasing levels of NMDA receptor activation by increasing the number of EPSPs that evoke complex spike bursts during long 5 $\mathrm{Hz}$ stimulation trains could enable the induction of LTP. Although we have not investigated the cellular mechanisms that regulate complex spike bursting, EPSPs evoked complex spike bursts in a highly stereotypic manner during $5 \mathrm{~Hz}$ stimulation, and we found that different stimulation patterns could be used to manipulate the total number of coincident EPSP and complex spike bursts evoked by a given number of $5 \mathrm{~Hz}$ stimulation pulses (Figs. 3C,D, 4). When 900 pulses of $5 \mathrm{~Hz}$ stimulation were delivered as six trains of 150 pulses (intertrain interval, $20 \mathrm{sec}$ ) there was a more than twofold increase in complex spike bursting in 9 of 12 experiments (Fig. $4 C$; the percentage of EPSPs that evoked complex spike bursts was increased to $70 \%$ during patterned stimulation compared with $27 \%$ during a continuous train). Consistent with the hypothesis that increasing the amount of EPSP and complex spike burst coincidence should enable the induction of LTP during long trains of $5 \mathrm{~Hz}$ stimulation, this pattern of stimulation induced significant LTP (Fig. 4D). In the three experiments in which patterned stimulation failed to enhance complex spike bursting (19\% of the EPSPs evoked complex spike bursts), no LTP was observed (fEPSPs were 109.6 $\pm 5.2 \%$ of baseline). We also examined the effects of delivering 300 pulses of $5 \mathrm{~Hz}$ stimulation as two 150 pulse trains (intertrain interval, 10 sec). Here the EPSP and complex spike burst coincidence was increased (73\% of the EPSPs evoked complex spike bursts compared with $52 \%$ for a continuous train), and now 300 pulses of 5 Hz stimulation induced LTP (fEPSPs were potentiated to $153.8 \pm$ $18.2 \%$ of baseline; $n=6$; data not shown).

\section{DISCUSSION}

Five hertz synaptic stimulation induces complex spike bursting in CA1 pyramidal cells

During $5 \mathrm{~Hz}$ synaptic stimulation, EPSPs evoked complex spike bursts in CA1 pyramidal cells in a highly activity-dependent manner, suggesting that a complex interaction of voltage- and transmitter-activated ion channels underlies complex spike burst generation. Although our experiments focused on the role of complex spike bursting in LTP induction during low-frequency synaptic stimulation, some of our observations have implications regarding potential mechanisms that might contribute to complex spike burst generation. First, consistent with previous findings suggesting that a highly TTX-sensitive persistent $\mathrm{Na}^{+}$conductance contributes to complex spike bursting in CA1 pyramidal cells (Azouz et al., 1996; Jensen et al., 1996), we found that a low concentration of TTX suppressed complex spike bursting. Second, our observation that synaptic stimulation reliably elicits complex spike bursts, whereas previous findings indicate that 
A

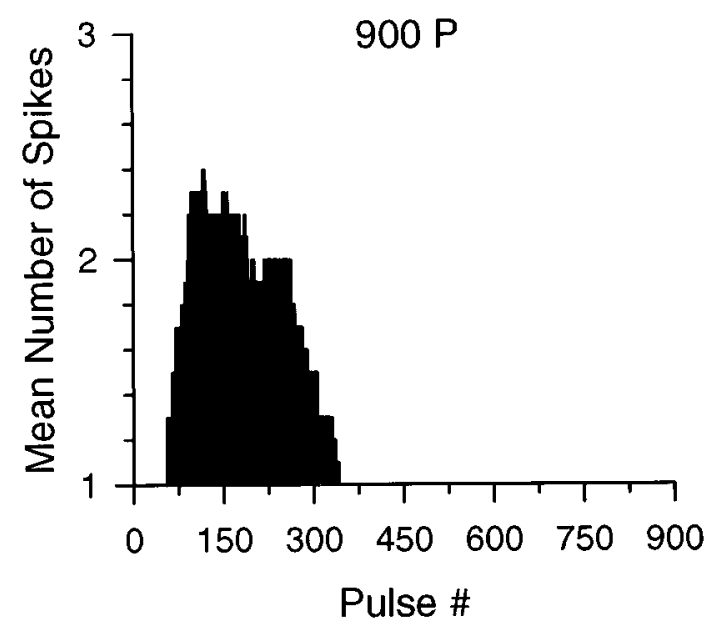

C

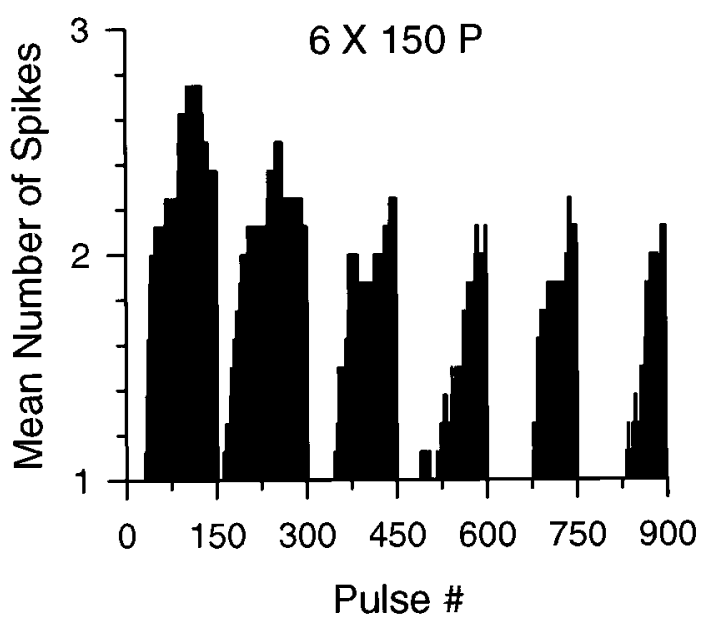

B

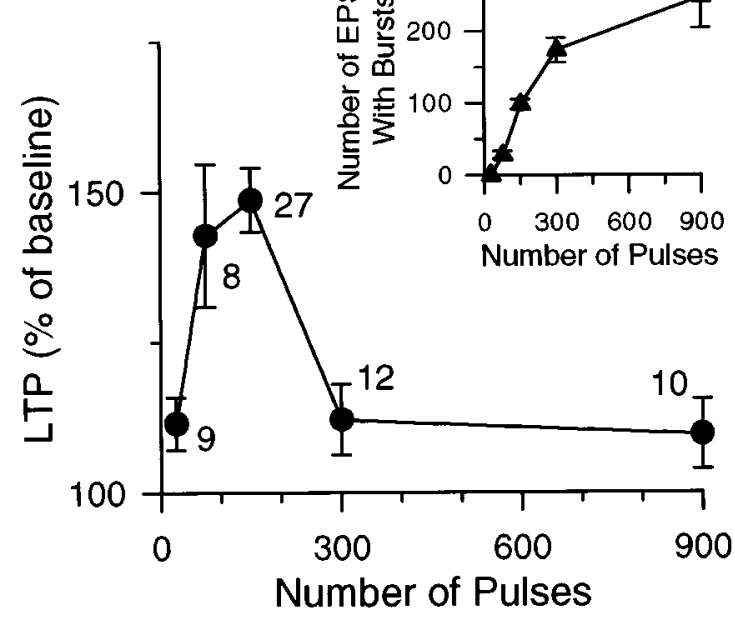

D

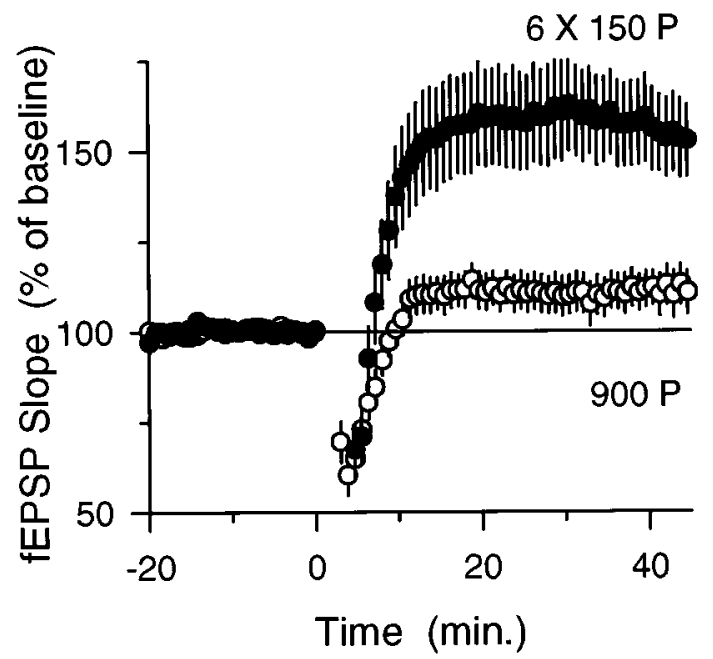

Figure 4. EPSP-complex spike burst coincidence regulates the induction of LTP. $A$, Mean number of EPSP-evoked spikes seen in the fEPSP recordings for each stimulation pulse during $3 \mathrm{~min}$ of $5 \mathrm{~Hz}$ stimulation $(n=10)$. For clarity, SEM bars, which ranged from 0 to 0.38 , are not shown. $B$, Summary of the amount of LTP induced by various duration trains of $5 \mathrm{~Hz}$ stimulation. Each point is the mean $( \pm$ SEM) amount of potentiation measured 45 min after $5 \mathrm{~Hz}$ stimulation. The number of experiments is indicated next to each point. Inset, Absolute number of EPSP-evoked complex spike bursts for each train of $5 \mathrm{~Hz}$ stimulation. $C$, Mean number of spikes seen in fEPSP recordings for each stimulation pulse during six 150-pulse trains of $5 \mathrm{~Hz}$ stimulation (intertrain interval, $20 \mathrm{sec} ; n=9$; SEM values ranged from 0 to 0.43). Note the large increase in the number of EPSPs that evoke bursting during patterned stimulation compared with continuous stimulation $(A) . D$, Nine hundred pulses of $5 \mathrm{~Hz}$ stimulation delivered as a single, continuous train (open symbols) fail to induce significant LTP (fEPSPs were $109.63 \pm 5.8 \%$ of baseline; $n=10$ ). In contrast, fEPSPs were potentiated to $150.3 \pm 10.4 \%$ of baseline when 900 stimulation pulses were delivered as six trains of 150 pulses ( filled symbols; $n=9 ; p<0.005$ compared with baseline). Data from the same experiments shown in $A$ and $C$.

depolarization of CA1 pyramidal cells in the absence of synaptic stimulation rarely elicits complex spike bursts (Jensen et al., 1994), suggests that synaptic conductances have an important role in the generation of complex spike bursts. One possibility is that complex spike bursting is enabled by the activity-dependent downregulation of inhibitory synaptic transmission that occurs during theta frequency stimulation of excitatory synaptic transmission in the hippocampal CA1 region (McCarren and Alger, 1985; Thompson and Gähwiler, 1989; Davies et al., 1990; Pacelli et al., 1991). Indeed, whereas inhibitory synaptic potentials are partially suppressed after the second pulse of a $5 \mathrm{~Hz}$ stimulation train (Davies et al., 1990; Pacelli et al., 1991), more complete suppression requires 5-10 sec of stimulation (McCarren and Alger, 1985), a time that corresponds to the 8-10 sec delay before complex spike bursting begins during $5 \mathrm{~Hz}$ stimulation observed in our experiments. Although decreased inhibitory synaptic transmission may contribute to complex spike burst generation, disinhibition alone cannot account for the pattern of complex spike bursting observed in our experiments, because complex spike bursting typically declined after $30 \mathrm{sec}$ of $5 \mathrm{~Hz}$ stimulation and ceased altogether after 1 min of stimulation (Fig. $4 A$ ), whereas inhibitory synaptic potentials remain depressed for the duration of $5 \mathrm{~Hz}$ stimulation (data not shown). Synaptic stimulation could also contribute to complex spike bursting by activating postsynaptic NMDA receptors, which have been proposed to contribute to burst firing in hippocampal pyramidal cells (Abraham and Kairiss, 1988; Poolos and Kocsis, 1990; Pongrácz et al., 1992). However, a high concentration of the NMDA receptor antagonist 
APV $(100 \mu \mathrm{M})$ did not block complex spike bursting in our experiments, suggesting that NMDA receptor activation is not required for EPSP-evoked complex spike bursting during $5 \mathrm{~Hz}$ stimulation. Clearly, much remains to be discovered regarding the synaptic and cellular mechanisms responsible for the activitydependent pattern of complex spike bursting elicited by $5 \mathrm{~Hz}$ trains of synaptic stimulation. However, the ability of $5 \mathrm{~Hz}$ synaptic stimulation to reliably elicit complex spike bursts in the hippocampal slice preparation should facilitate a more in-depth analysis of this phenomenon.

\section{Complex spike bursts enable the induction of LTP during $5 \mathrm{~Hz}$ stimulation}

Recent studies investigating phenomena ranging from the elementary properties of synaptic transmission to the behavioral correlates of single-unit firing in vivo suggest that the complex spike mode of action potential firing in hippocampal pyramidal cells represents an informationally rich form of neuronal activity (for review, see Lisman, 1997). For instance, hippocampal pyramidal cells are often preferentially activated when animals enter specific locations with the environment (O'Keefe and Dostrovsky, 1971; O'Keefe, 1976; Muller, 1996), and the region in which a given cell is maximally activated, called its place field, is more precisely defined by complex spike bursting than by single spikes (Otto et al., 1991). Complex spike bursting in ensembles of hippocampal neurons may thus generate a more accurate internal representation of position in the external environment than single spikes (Lisman, 1997). In our experiments we found that (1) LTP is induced by strong-intensity $5 \mathrm{~Hz}$ synaptic stimulation that evokes postsynaptic complex spike bursting but not by weakintensity $5 \mathrm{~Hz}$ stimulation that fails to evoke complex spike bursts; (2) LTP is blocked by low concentrations of TTX that have little effect on the generation of single postsynaptic action potentials but block complex spike bursting; (3) strong-intensity $5 \mathrm{~Hz}$ stimulation trains that terminate before complex spike bursting begins fail to induce LTP; (4) LTP is induced by pairing synaptic potentials with simulated complex spike bursts evoked by antidromic stimulation but not by pairing EPSPs with single antidromic action potentials; (5) the induction of LTP is inhibited by patterning stimulation protocols to reduce complex spike bursting during short trains of $5 \mathrm{~Hz}$ stimulation; and (6) patterned stimulation protocols that increase complex spike bursting during long trains of $5 \mathrm{~Hz}$ stimulation enable LTP induction. Our results thus indicate that, in addition to their proposed role in information coding, postsynaptic complex spike bursts also have an important role in synaptic plasticity.

Although the patterns of neuronal activity that induce LTP in vivo are unknown, previous studies have shown that patterns of presynaptic fiber stimulation that mimic complex spike bursting can induce LTP. For instance, LTP can be induced in vitro by presynaptic bursts of high-frequency stimulation delivered at the theta frequency (Larson et al., 1986) or in phase with carbacholinduced theta frequency-like activity (Huerta and Lisman, 1993, 1995). Likewise, bursts of high-frequency presynaptic stimulation applied during the positive phase of the theta rhythm in vivo induce robust LTP (Hölscher et al., 1997). Our results indicate that in addition to this potential presynaptic role for complex spike bursting, postsynaptic complex spike bursts enable the induction of LTP in the absence of presynaptic bursting. One possibility suggested by our findings is that back-propagating action potentials during postsynaptic complex spike bursting in vivo (Buzáki et al., 1996) produce a state of heightened sensitivity during which even low frequencies of presynaptic activity can readily induce LTP. Because action potentials can be initiated in pyramidal cell dendrites under some conditions (Spencer and Kandel, 1961; Wong et al., 1979; Poolos and Kocsis, 1990; Turner et al., 1991; Spruston et al., 1995), our results do not rule out the possibility that dendritically initiated, rather than backpropagating, complex spike bursts produce such an effect.

Because brief trains of $5 \mathrm{~Hz}$ stimulation (75 and 150 pulses) induce LTP, our results indicate that unpotentiated synapses that are coactive with postsynaptic complex spike bursts will readily undergo LTP, even when relatively few EPSPs evoke complex spike bursts. In contrast, little LTP was induced by longer trains of continuous $5 \mathrm{~Hz}$ stimulation (300 and 900 pulses), even though the total number of EPSP-evoked complex spike bursts was several times greater than that elicited by shorter trains of $5 \mathrm{~Hz}$ stimulation. LTP could be induced by long trains of $5 \mathrm{~Hz}$ stimulation when patterned stimulation was used to increase the number of EPSP-evoked complex spike bursts. Thus, the amount of coincident presynaptic and postsynaptic activity (EPSP-evoked complex spike bursts) required to induce LTP increases during 5 $\mathrm{Hz}$ stimulation in a manner similar to that predicted by the BCM (Bienenstock, Cooper, Muro) model of synaptic plasticity (Bear et al., 1987), which proposes that the threshold level of coincident synaptic activity needed to induce persistent increases in synaptic strength increases with the induction of LTP. Because previous studies have shown that protein phosphatase inhibitors enable the induction of LTP during long trains of $5 \mathrm{~Hz}$ stimulation (Thomas et al., 1996), an activity-dependent activation of protein phosphatases may underlie the need for increased levels of EPSP and complex spike burst coincidence to induce LTP during long trains of $5 \mathrm{~Hz}$ stimulation. Physiologically, this need for higher levels of coincident EPSP and complex spike bursts to induce LTP as stimulation extends beyond that minimally required for LTP induction may act to restrict LTP to only those synapses that reliably evoke complex spike bursting (Fig. 4, compare $A, C$ and $D$ ). Thus, LTP induced by EPSP-evoked complex spike bursting during lowfrequency stimulation is truly Hebbian (Hebb, 1949); it not only requires postsynaptic action potentials but, at least for longduration trains, also requires that EPSPs consistently contribute to postsynaptic bursting.

Hippocampal pyramidal cells often fire complex spike bursts when animals occupy specific locations within the environment (Ranck, 1973; Muller, 1996). Although place-specific firing of pyramidal cells is probably generated endogenously via locomotor cues that provide information about position in the external environment, synaptic inputs that convey place-specific sensory information about the environment are thought to become linked, or bound, to firing of a particular place cell through a process such as LTP (McNaughton et al., 1996). Our results, which show that synaptic inputs active during complex spike bursting undergo robust LTP, suggest how this latter process may occur in vivo and provide a cellular basis for understanding how the theta frequency complex spike bursting observed in CA1 pyramidal cells during behaviors associated with learning (Otto et al., 1991) might contribute to memory formation.

\section{REFERENCES}

Abraham WC, Kairiss EW (1988) Effects of the NMDA antagonist 2AP5 on complex spike discharge by hippocampal pyramidal cells. Neurosci Lett 89:36-42.

Azouz R, Jensen MS, Yaari Y (1996) Ionic basis of spike afterdepolarization and burst generation in adult rat hippocampal CA1 pyramidal cells. J Physiol (Lond) 492:211-223. 
Bear MF, Cooper LN, Ebner FF (1987) A physiological basis for a theory of synapse modification. Science 237:42-48.

Bland BH (1990) Physiology and pharmacology of hippocampal formation theta rhythms. Prog Neurobiol 26:1-54.

Bliss TVP, Collingridge GL (1993) A synaptic model of memory: longterm potentiation in the hippocampus. Nature 361:31-39.

Blitzer RD, Wong T, Nouranifar R, Iyengar R, Landau EM (1995) Postsynaptic cAMP pathway gates early LTP in the hippocampal CA1 region. Neuron 15:1403-1414.

Bolshakov VY, Siegelbaum SA (1994) Postsynaptic induction and presynaptic expression of hippocampal long-term depression. Science 264:1148-1152.

Buzáki G, Penttonen M, Nádasdy Z, Bragin A (1996) Pattern and inhibition-dependent invasion of pyramidal cell dendrites by fast spike in the hippocampus in vivo. Proc Natl Acad Sci USA 93:9921-9925.

Cummings JA, Mulkey RM, Nicoll RA, Malenka RC (1996) $\mathrm{Ca}^{2+}$ signaling requirements for long-term depression in the hippocampus. Neuron 16:825-833.

Davies CH, Davies SN, Collingridge GL (1990) Paired-pulse depression of monosynaptic GABA-mediated inhibitory postsynaptic responses in rat hippocampus. J Physiol (Lond) 424:513-531.

Debanne D, Gähwiler BH, Thompson SM (1996) Cooperative interactions in the induction of long-term potentiation and depression of synaptic excitation between hippocampal CA3-CA1 cell pairs in vitro. Proc Natl Acad Sci USA 93:11225-11230.

Fox S, Ranck JB (1975) Localization and anatomical identification of theta and complex spike cells in dorsal hippocampal formation of rats. Exp Neurol 49:299-313.

Fujii S, Saito K, Miyakawa H, Ito K, Kato H (1991) Reversal of longterm potentiation (depotentiation) induced by tetanus stimulation of the input to CA1 neurons of guinea pig hippocampal slices. Brain Res 555:112-122.

Grover LM, Teyler TJ (1990) Two components of long-term potentiation induced by different patterns of afferent activation. Nature 347:477-479.

Gustafsson B, Wigström H (1990) Basic features of long-term potentiation in the hippocampus. Semin Neurosci 2:321-333.

Hebb DO (1949) The organization of behavior. New York: Wiley.

Hölscher C, Anwyl R, Rowan MJ (1997) Stimulation on the positive phase of hippocampal theta rhythm induces long-term potentiation that can be depotentiated by stimulation on the negative phase in area CA1 in vivo. J Neurosci 15:6470-6477.

Huang Y-Y, Colino A, Selig DK, Malenka RC (1992) The influence of prior synaptic activity on the induction of long-term potentiation. Science 255:730-733.

Huerta PT, Lisman JE (1993) Heightened synaptic plasticity of hippocampal CA1 neurons during a cholinergically induced rhythmic state. Nature 364:723-725.

Huerta PT, Lisman JE (1995) Bidirectional synaptic plasticity induced by a single burst during cholinergic theta oscillation in CA1 in vitro. Neuron 15:1053-1063.

Ito K-I, Miura M, Furuse H, Zhixiong C, Kato H, Yasutomi D, Inoue T, Mikoshiba K, Kimura T, Sakakibara S, Miyakawa H (1995) Voltagegated $\mathrm{Ca}^{2+}$ channel blockers, $\omega$-AgaIVA and $\mathrm{Ni}^{2+}$, suppress the induction of theta-burst induced long-term potentiation in guinea-pig hippocampal CA1 neurons. Neurosci Lett 183:112-115.

Jensen MS, Azouz R, Yaari Y (1994) Variant firing patterns in rat hippocampal pyramidal cells modulated by extracellular potassium. J Neurophysiol 71:831-839.

Jensen MS, Azouz R, Yaari Y (1996) Spike after-depolarization and burst generation in adult rat hippocampal CA1 pyramidal cells. J Physiol (Lond) 492:199-210.

Jester JM, Campbell LW, Sejnowski TJ (1995) Associative EPSP-spike potentiation induced by pairing orthodromic and antidromic stimulation in rat hippocampal slices. J Physiol (Lond) 484:689-705.

Johnston D, Williams S, Jaffe D, Gray R (1992) NMDA receptorindependent long-term potentiation. Annu Rev Physiol 54:489-505.

Kandel ER, Spencer WA (1961) Electrophysiology of hippocampal neurons. II. After-potentials and repetitive firing. J Neurophysiol 25:243-259.

Larson J, Wong D, Lynch G (1986) Patterned stimulation at the theta frequency is optimal for the induction of hippocampal long-term potentiation. Brain Res 368:347-350.

Lisman JE (1994) The CaM kinase II hypothesis for the storage of synaptic memory. Trends Neurosci 17:406-412.

Lisman JE (1997) Bursts as a unit of neural information: making unreliable synapses reliable. Trends Neurosci 20:38-43.
Magee JC, Johnston D (1995) Synaptic activation of voltage-gated channels in the dendrites of hippocampal pyramidal neurons. Science 268:301-304.

Magee JC, Johnston D (1997) A synaptically controlled, associative signal for Hebbian plasticity in hippocampal neurons. Science 275:209-212.

Markram H, Lübke J, Frotscher M, Sakmann B (1997) Regulation of synaptic efficacy by coincidence of postsynaptic APs and EPSPs. Science 275:213-215.

Mayford M, Wang J, Kandel ER, O'Dell TJ (1995) CaMKII regulates the frequency-response function of hippocampal synapses for the production of both LTD and LTP. Cell 81:891-904.

McCarren M, Alger BE (1985) Use-dependent depression of IPSPs in rat hippocampal pyramidal cells in vitro. J Neurophysiol 53:557-571.

McNaughton BL, Barnes CA, Gerrard JL, Gothard K, Jung MW, Knierim JJ, Kudrimoti H, Qin Y, Skaggs WE, Suster M, Weaver KL (1996) Deciphering the hippocampal polyglot: the hippocampus as a path integration system. J Exp Biol 199:173-185.

Mulkey RM, Malenka RC (1992) Mechanisms underlying induction of homosynaptic long-term depression in area CA1 of the hippocampus. Neuron 9:967-975.

Muller R (1996) A quarter of a century of place cells. Neuron 17:813-822.

Nicoll RA, Kauer JA, Malenka RC (1988) The current excitement in long-term potentiation. Neuron 1:97-103.

O'Dell TJ, Kandel ER (1994) Low-frequency stimulation erases LTP through an NDMA receptor-mediated activation of protein phosphatases. Learn Mem 1:129-139.

O'Keefe J (1976) Place units in the hippocampus of the freely moving rat. Exp Neurol 51:78-109.

O'Keefe J, Dostrovsky J (1971) The hippocampus as a spatial map. Preliminary evidence from unit activity in the freely moving rat. Brain Res 34:171-175.

Oliet SHR, Malenka RC, Nicoll RA (1997) Two distinct forms of longterm depression coexist in CA1 hippocampal pyramidal cells. Neuron 18:969-982.

Otto T, Eichenbaum H, Wiener SI, Wible CG (1991) Learning-related patterns of CA1 spike trains parallel stimulation parameters optimal for inducing hippocampal long-term potentiation. Hippocampus 1:181-192.

Pacelli GJ, Su W, Kelso SR (1991) Activity-induced decrease in early and late inhibitory synaptic conductances in hippocampus. Synapse 7:1-13.

Pongrácz F, Poolos NP, Kocsis JD, Shepherd GM (1992) A model of NMDA receptor-mediated activity in dendrites of hippocampal CA1 pyramidal neurons. J Neurophysiol 68:2248-2259.

Poolos NP, Kocsis JD (1990) Dendritic action potentials activated by NMDA receptor-mediated EPSPs in CA1 pyramidal cells. Brain Res 524:342-346.

Ranck JB (1973) Studies on single neurons in dorsal hippocampal formation and septum in unrestrained rats. Part I. Behavioral correlates and firing repertoires. Exp Neurol 41:461-531.

Scharfman HE, Sarvey JM (1985) Postsynaptic firing during repetitive stimulation is required for long-term potentiation in hippocampus. Brain Res 331:267-274.

Spencer WA, Kandel ER (1961) Electrophysiology of hippocampal neurons. IV. Fast prepotentials. J Neurophysiol 24:272-285.

Spruston N, Schiller Y, Stuart B, Sakmann B (1995) Activity-dependent action potential invasion and calcium influx into hippocampal CA1 dendrites. Science 268:297-300.

Suzuki SS, Smith GK (1985) Burst characteristics of hippocampal complex spike cells in the awake rat. Exp Neurol 89:90-95.

Suzuki SS, Smith GK (1988) Spontaneous EEG spikes in the normal hippocampus. III. Relations to evoked potentials. Electroencephalogr Clin Neurophysiol 69:541-549.

Talbot MJ, Sayer RJ (1996) Intracellular QX-341 inhibits calcium currents in hippocampal CA1 pyramidal neurons. J Neurophysiol 76:2120-2124.

Thomas MJ, Moody TD, Makhinson M, O'Dell TJ (1996) Activitydependent $\beta$-adrenergic modulation of low frequency stimulation induced LTP in the hippocampal CA1 region. Neuron 17:475-482.

Thompson SM, Gähwiler BH (1989) Activity-dependent disinhibition. I. Repetitive stimulation reduces IPSP driving force and conductance in the hippocampus in vitro. J Neurophysiol 61:512-533.

Turner RW, Meyers DER, Richardson TL, Baker JL (1991) The site for initiation of action potential discharge over the somatodendritic axis rat hippocampal CA1 pyramidal neurons. J Neurosci 11:2270-2280.

Wong RKS, Prince DA, Basbaum AI (1979) Intradendritic recordings from hippocampal neurons. Proc Natl Acad Sci USA 76:986-990. 